\section{Tropical Journal of Pathology and Microbiology}

2020 Volume 6 Number 8 November-December

\title{
Causes of sudden death - autopsy review in a tertiary referral center
}

\author{
Choukimath S. M. ${ }^{1}$, Naik M. ${ }^{2 *}$ \\ DOI: https://doi.org/10.17511/jopm.2020.i08.04
}

1 S.M. Choukimath, Associate Professor, Department of Pathology, Karnataka Institute of Medical Sciences, Hubballi, Karnataka, India.
2* Megha Naik, Post-Graduate, Department of Pathology, Karnataka Institute of Medical Sciences, Hubballi, Karnataka, India.

Background: The incidence of sudden death has been increasing steadily all over the world particularly in the urban population for the last 5 years. World health organization [WHO] has defined sudden death as "Death within 24 hrs from the onset of symptoms". It can be defined as deaths that are sudden, unexpected, clinically unexplained, or otherwise obscure even though there need to be no unnatural element in their causation. Materials and methods: Complete analysis and review of all autopsy/post-mortem specimens received in the Department of Pathology, KIMS, Hubballi between September 2017 to June 2019 done to find out the cause of death. Results: During the study period, a total of 153 cases of sudden death were received, age ranged from 6 months to 72 years, with male preponderance. The cause of death were, 67 cases - cardiac causes $[43.7 \%], 15$ cases- respiratory causes $[9.8 \%], 7$ cases of sepsis $[4.5 \%], 6$ cases of Miliary TB [3.9\%], CNS- 5 cases [3.2\%], Hepatobiliary [2.6\%], Renal- 2 cases [1.3\%], Gastrointestinal 2 cases [1.3\%] Malignancy - 1 case [0.65\%], Inconclusive 44 - cases [ $28.7 \%$ ]. Conclusion: This study concludes that sudden death can occur at any age with the most common cause being cardiac diseases and few among these are preventable. Therefore, creating awareness about the risk factors and prevention of disease progression can reduce the incidence of sudden deaths.

Keywords: Autopsy, Cardiac cause, Non-cardiac cause, Sudden death

Corresponding Author

Megha Naik, Post-Graduate, Department of Pathology, Karnataka Institute of Medical Sciences, Hubballi, Karnataka, India. Email: meghanaik18@gmail.com
How to Cite this Article To Browse

Choukimath SM, Naik M. Causes of sudden death autopsy review in a tertiary referral center. Trop J Pathol Microbiol. 2020;6(8):481-485.

Available From

https://pathology.medresearch.in/index.php/jopm/ar ticle/view/504

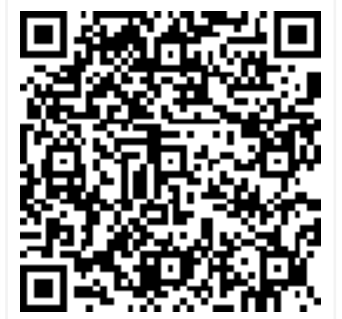

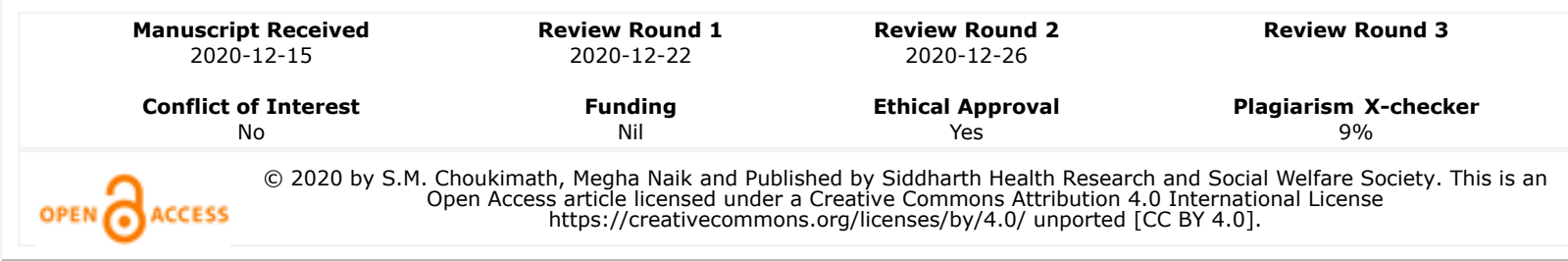




\section{Introduction}

Incidence of sudden death [SD] has been increasing steadily all over the world particularly in the urban population since the last 5 years $[1,2]$. World health organization [WHO] has defined sudden death as "death within $24 \mathrm{hrs}$ from the onset of symptoms". It can be defined as deaths that are sudden, unexpected, clinically unexplained, or otherwise obscure even though there need to be no unnatural element in their causation [3]. Such a rapid death is often attributed to a cardiac cause.

Despite the modernization in medicine, the diagnosing tool lack inaccuracy to find the clinical cause of death in comparison with autopsy cause of death [4].

Now the issue of the death certificate is mandatory according to the Birth and Death Registration Act 1969. Hence all the unexplained deaths must undergo an autopsy to determine the exact cause of death.

So, the main aim of this study is to establish the most possible cause of death and provide the final diagnosis.

\section{Materials and Methods}

Type of study: Retrospective study

Place and duration of study: Complete analysis and review of all autopsy/post-mortem specimens received in the Department of Pathology, Karnataka Institute of Medical Sciences, Hubballi, between September 2017 to June 2019 was done to find out the cause of death.

Sample collection: Clinical details and clinical cause of death were derived from the Mortuary Registration Form. All the specimens received in $10 \%$ neutral buffered formalin for autopsy were grossly examined in detail and findings were noted. Multiple tissue bits of size $1 \times 1 \times 0.3 \mathrm{~cm}$ were submitted for histopathological examination. After processing, $4 \mu$ thickness sections were cut and stained with hematoxylin and eosin. Microscopic findings were reported and data were analyzed.

Inclusion criteria: Death within 24 hours/ fulfilling the criteria of sudden death

\section{Exclusion criteria:}

01. Death more than 24 hours/not fulfilling the criteria of sudden death,
02. Snakebite,

03. Road traffic accident,

04. Electrocution,

05. Suicide and

06. Homicide cases.

Ethical committee clearance: Approval was obtained from the Institutional Ethics Committee before the commencement of the study.

Statistics: Statistical analysis was carried out using SPSS software v.21. Data were expressed in frequencies and percentages.

\section{Results}

In 1 year 9 months duration between September 2017 to June 2019, a total of 475 autopsies were done in the Department of Pathology KIMS Hubballi. Among these 143 cases were of sudden death.

In these sudden death cases males were predominant $90 \%(n=129)$ and Females were $10 \%$ $(n=14)$ with $M: F$ ratio $=9.2: 1$.

Age ranged from 1 month to 77 years. Maximum cases of sudden death were seen in the age group $31-40 \mathrm{yrs}$ of age. Mean age $42.35 \pm 14.9$ years [Figure 1].

Among these 143 cases, the majority of cases of sudden death were due to cardiac cause $(N=67)$ i.e. $46.9 \%$. The age group affected by sudden cardiac death was 41-50 years. Non - cardiac causes of sudden death included pulmonary, hepatobiliary, CNS, Gastrointestinal, and Renal causes [Figure 2, Table 1].

Table-1: Causes of death.

\begin{tabular}{|c|c|c|c|}
\hline \multicolumn{2}{|c|}{ Cause of Death } & Frequency (N) & Percent (\%) \\
\hline \multicolumn{2}{|c|}{ Cardiac } & 67 & 46.9 \\
\hline \multicolumn{2}{|c|}{ Pulmonary } & 13 & 9.1 \\
\hline \multicolumn{2}{|c|}{ Central Nervous System } & 7 & 4.9 \\
\hline \multicolumn{2}{|l|}{ Renal } & 2 & 1.4 \\
\hline \multicolumn{2}{|c|}{ Hepatobiliary } & 5 & 3.5 \\
\hline \multicolumn{2}{|c|}{ Gastrointestinal } & 2 & 1.4 \\
\hline \multirow[t]{4}{*}{ Others } & Miliary TB & 6 & 4.2 \\
\hline & Sepsis & 6 & 4.2 \\
\hline & Malignancy & 1 & 0.7 \\
\hline & Total & 13 & 9.1 \\
\hline \multicolumn{2}{|c|}{ Autolysed } & 10 & 7.0 \\
\hline \multicolumn{2}{|c|}{ Inconclusive } & 24 & 16.8 \\
\hline \multicolumn{2}{|l|}{ Total } & 143 & 100 \\
\hline
\end{tabular}




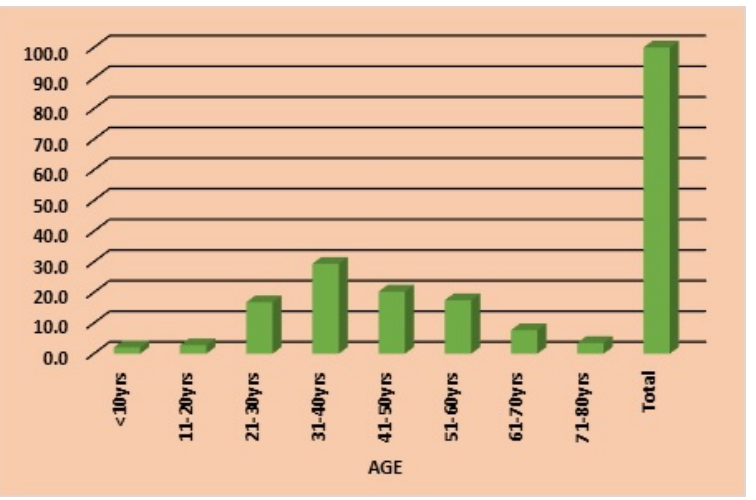

Fig-1: Age distribution.

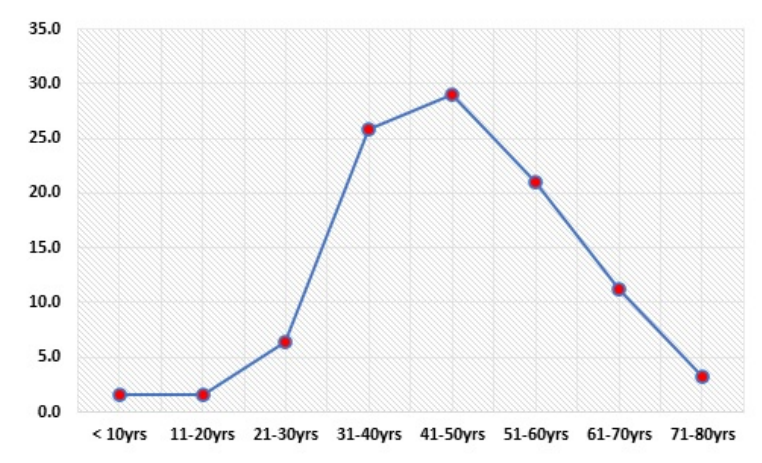

Fig-2: Age distribution in cardiac causes of death.

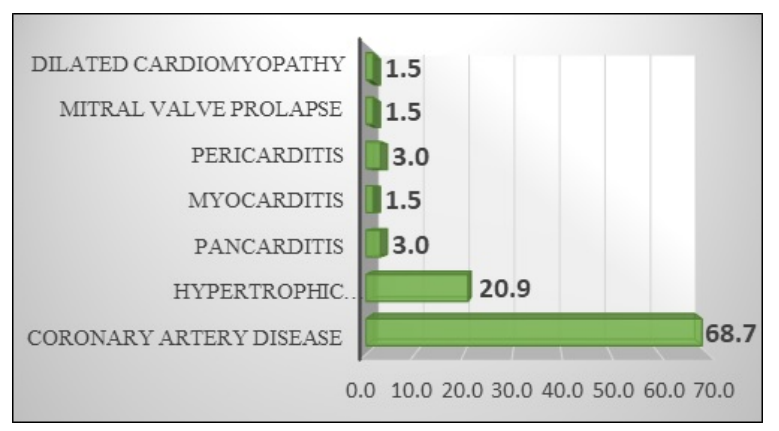

Fig-3: Cardiac causes of sudden death.

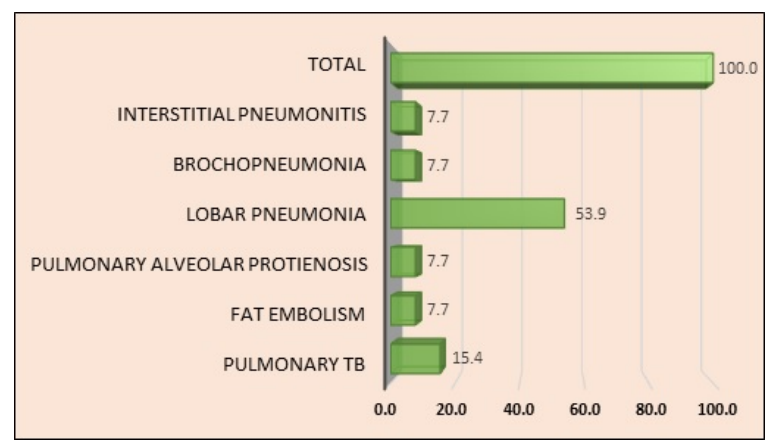

Fig-4: Pulmonary causes of sudden death.
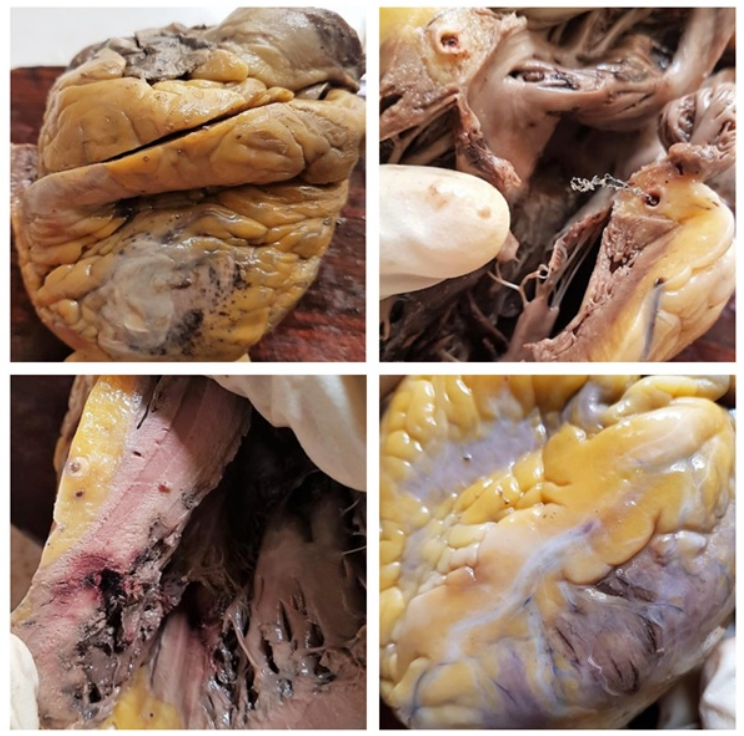

Fig-5: A-Healed myocardial Infraction. BCoronary artery disease with the stent in situ.

C and D- Complete occlusion of the left coronary artery (Arrow) with red mottling and myocardial rupture.

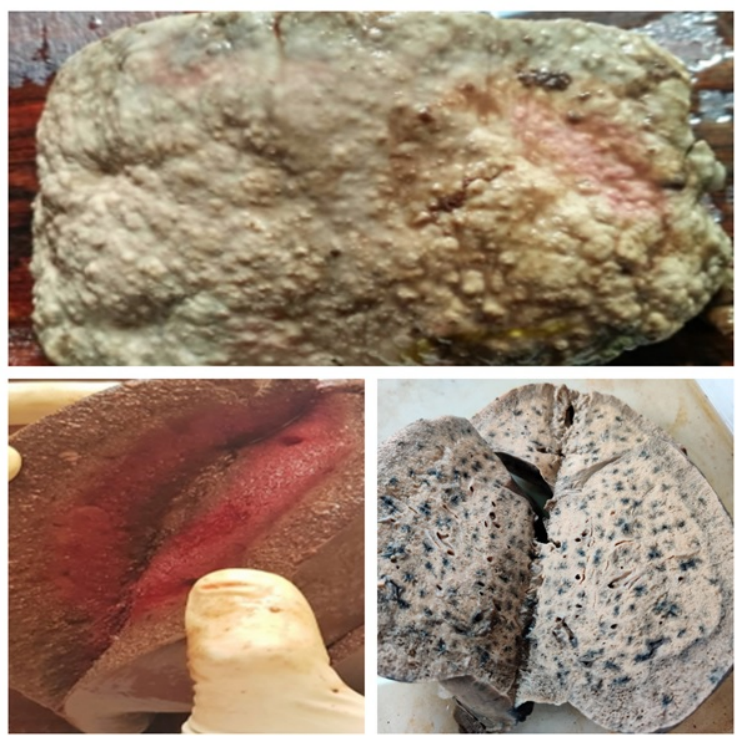

Fig-6: A and B- Miliary tuberculosis of liver and spleen respectively. C- Lobar pneumonia.

\section{Cardiac causes:}

Among these 143 cases, the majority of cases of sudden death were due to cardiac cause $(\mathrm{N}=67)$ i.e. $46.9 \%$. Age group affected in sudden cardiac death 41-50 years [Figure 2]. The majority of the cases were Coronary artery diseases [68.7\%] [Table 1]. 
Other causes were hypertrophic cardiomyopathy, pancarditis, myocarditis, mitral valve prolapse, and dilated cardiomyopathy [Figure 3].

\section{Non-Cardiac causes:}

Among non - cardiac causes of sudden death, pulmonary causes were most common (9.1\%) and Lobar pneumonia constituted a maximum number of cases $(53.9 \%)$. Other causes were pulmonary tuberculosis, fat embolism, pulmonary alveolar proteinosis, bronchopneumonia, and interstitial pneumonitis [Figure 4].

\section{Discussion}

Most of the literature reveals that cardiovascular diseases are more common causes of sudden deaths. In a study by Pandian et al [5], a total of 120 cases were studied wherein $55.83 \%$ of deaths were due to cardiac causes $(n=67)$. Among these $49.25 \%$ of deaths were due to Coronary artery disease (CAD). Non-cardiac causes were mostly due to pulmonary diseases (37.74\%), hepatobiliary diseases (30.19\%), septicemia (18.87\%), GI $(3.77 \%)$, CNS $(7.55 \%)$, Malignancy $(1.87 \%)$.

In the present study, out of 143 cases, $46.9 \%$ of deaths were due to cardiac causes $(n=67)$. Among these $68.7 \%$ of deaths were due to CAD. Noncardiac causes were mostly due to pulmonary diseases (9.1\%), hepatobiliary (3.5\%), septicaemias $(4.2 \%)$, GI $(1.4 \%)$, CNS $(4.9 \%)$, Malignancy- Neuroendocrine carcinoma (0.7\%).

In a study done by Eckart et al. [6] among 604 cases studied most common was CAD (73.2\%), HCM (5.6\%), Myocarditis (2.2\%), DCM (4.2\%), Anomalous coronary artery (4\%), right ventricular dysplasia (1\%), Unexplained causes (10.6\%), others $(1.5 \%)$.

In a study done by Rao D et al, a total of 2449 autopsies were conducted of which 204 cases were due to sudden cardiac deaths [SCD]. The highest SCDs were reported in the 50-60 years age group (62.24\%; $n-127)$, followed closely by the age group 60-69yrs (28.43\%, $\mathrm{n}-58)$. The male to female ratio was around 10:1. In 24 (11.8\%) cases major narrowing was noted in both the main coronaries, in $87(42.6 \%)$ cases in the left anterior descending coronary artery [LAD], and in $18(51.5 \%)$ cases in the right coronary artery [RCA].
$56.86 \%]$ and myocardial infarction [n - 104; $50.9 \%]$. In the present study out of 143 cases of sudden death, the age ranged from 1 month to $77 y$ rs with maximum sudden death was seen in the age group $31-40$ years of age. Mean age $42.35 \pm 14.9$ years. There was male predominance $90 \%(n=129)$ and Females were $10 \%(n=14)$ with $M: F$ ratio $=9.2: 1$. Among Sudden deaths, $46.9 \%$ $(n=67)$ were due to cardiovascular disease. CAD $(68.7 \%)$ was found to be the major cardiac cause. Followed by HCM (20.9\%), Pericarditis (3\%), Myocarditis (1.5\%), Pancarditis (3\%), MV prolapse $(1.5 \%)$, DCM (1.5\%).16.8\% of cases cause was inconclusive, as there were no active lesions. But death could have been attributed to arrhythmias or coronary vasospasm. Most of the other literature [811] reveals cardiovascular disease as the common cause of SD.

\section{Conclusion}

This study concludes that sudden death can occur at any age with the most common cause being cardiac diseases and few among these are preventable. Therefore, creating awareness about the risk factors and prevention of disease progression can reduce the incidence of sudden deaths.

\section{What does the study add to the existing knowledge?}

Even though sudden deaths are inevitable, creating awareness about risk factors and the progression of the disease can prevent a few of the sudden deaths.

\section{Author's contribution}

Dr. S.M Choukimath: Concept and design of the study, Data acquisition, final approval of the version to be published.

Dr. Megha M Naik: Literature search, manuscript preparation and editing, data analysis, and interpretation of data.

\section{Reference}

01. Goldberger JJ, Basu A, Boineau R, Buxton AE, Cain ME, Canty Jr JM, et al. Risk stratification for sudden cardiac death a plan for the future. Circulation. 2014;129(4)516-526.

doi: 10.1161/CIRCIMAGING.117.006819 [Crossref]

The major cardiac pathology resulting in sudden death was coronary artery disease [n - 116; 
02. Harmaon KG, Asif IM, Klossner D, Drezner JA. Incidence of sudden cardiac death in national collegiate athletic association athletes. Circulation. 2011;123(15)1594-600.

doi: 10.1136/bjsports-2014-093872 [Crossref]

03. WHO. International classification of Diseases and related health problems 10th revision(ICD 10) version for 2010.

Available from [Article] [Crossref]

04. Goldman L, Sayson R, Robbins S, Cohn LH, Bettman $M$, Weisberg $M$. The value of the autopsy in three medical eras. N Eng J Med. $1983 ; 308(17) 1000-1005$.

doi: 10.1056/NEJM198304283081704 [Crossref]

05. Pandian JR, Laishram RS, Kumar LD, Phuritsabam P, Debnath K. Autopsy review of sudden deaths in a tertiary hospital of northeastern India. J Med Soc. 2014;28(3)145-148.

doi: $10.4103 / 0972-4958.148495$ [Crossref]

06. Eckart RE, Scoville SL, Campbell CL, Shry EA, Stajduhar KC, Potter RN, et al. Sudden death in young adults: a 25-year review of autopsies in military recruits. Ann Int Med. 2004; 141(11)829-834.

doi: $\quad 10.7326 / 0003-4819-141-11-200412070-00005$ [Crossref]
07. Rao D, Sood D, Pathak P, Dongre SD. A cause of Sudden Cardiac Deaths on Autopsy Findings- a Four-Year Report. Emergency. 2014;2(1)12.

doi: 10.22037/EMERGENCY.V2I1.5766 [Crossref]

08. Thomas AC, Knapman PA, Krikler DM, Davies MJ. Community study of the causes of "natural" sudden deaths. BMJ. 1988;297(6661)14531456 .

doi: $\quad 10.1136 / \mathrm{bmj} .297 .6661 .1453 \quad$ [Crossref]

09. Chugh SS, Kelly KL, Titus JL. Sudden cardiac death with apparently normal heart. Circulation. 2000;102(6)649-54.

doi: $10.1023 / \mathrm{A}: 1013254132689$ [Crossref]

10. Doolan A, Semsarian C, Langlois N. Causes of sudden cardiac death in young Australians. Med J Aust. $2004 ; 180$ (3)110-112.

doi: $10.5694 /$ j.1326-5377.2004.tb05830.x [Crossref]

11. Sudha $M L$, Sundaram S, Purushothaman $K R$, Kumar PS, Prathiba D. Coronary atherosclerosis in sudden cardiac death- An autopsy study. Indian J Pathol Microbiol. 2009;52(4)486. doi: $10.4103 / 0377-4929.56130$ [Crossref] 